\title{
O DIREITO, ONTEM E HOJE. CRÍTICA AO NEOPOSITIVISMO CONSTITUCIONAL. INSUFICIÊNCIA DOS DIREITOS HUMANOS ${ }^{1}$
}

\author{
LAW, YESTERDAY AND TODAY. A CRITICAL TO THE CONSTITUTIONAL NEOPOSITIVISM. THE \\ INSUFFICIENCE OF THE HUMAN RIGHTS
}

Antonio Junqueira de Azevedo ${ }^{2}$

\begin{abstract}
Resumo:
O Autor faz, de início, uma sintética exposição da evolução histórica das relações entre Direito e religião e Direito e moral. Depois, após examinar o paradigma do Direito Natural e do positivismo legal, passa a ver a situação atual do raciocínio jurídico baseado na Constituição e nos direitos humanos. Critica, finalmente, o neopositivismo constitucional, por ser excessivamente normativo, e os direitos humanos, por não incluir o valor da vida em geral. Sugere a adoção da idéia de Direito como sistema e a admissão mais intensa do respeito à vida.

Palavras-chaves: Direito. Sistema. Moral. Neopositivismo constitucional. Direitos humanos. Valor-vida.
\end{abstract}

\begin{abstract}
:
The Author begins doing and a syntethic exposition of the historical evolution of the relations between Law and religion and Law and moral. Then, after examine the paradigm of the Natural Law and the legal positivism, the Author starts to seek the current situation of the legal reasoning based in the Constitution and in human rights. Before, criticizes the constitutional neopositivism, because of its normative excess and the human rights for do not include the value of life in general. Finally, suggests the adoption of a system Law idea and admission of a more intense life respect.
\end{abstract}

Keywords: Law. System. Moral. Constitutional neopositivism. Human right. Value-life.

\section{Direito e Religião}

Quando se pensa nos povos antigos, nossa difusa cultura histórica traz à mente associações freqüentes e inevitáveis entre eles e determinadas atividades: aos egípcios, a construção de templos e pirâmides; aos gregos, a filosofia; aos fenícios, o comércio; aos hebreus, a religião; e assim por diante. O Direito está ligado aos romanos. Valeria a pena perguntar por quê. A razão, em palavras simples, não está tanto no conteúdo

\footnotetext{
Aula inaugural dos cursos jurídicos da Faculdade de Direito de Ribeirão Preto da Universidade de São Paulo.

2 Diretor da Faculdade de Direito de Ribeirão Preto da Universidade de São Paulo. Ex-Diretor e Professor Titular de Direito Civil da Faculdade de Direito da Universidade de São Paulo. Membro do Conselho Editorial da Revista da Faculdade de Direito da Universidade de São Paulo. E-mail prof.junqueira@terra.com.br
} 
das normas jurídicas que herdamos - eis que as leis de hoje são muito diferentes das de ontem e o mundo atual é muito diverso daquele de 2.000 anos atrás -; a explicação está antes numa espécie de ato fundador cujas conseqüências permanecem até hoje.

Esse ato foi a separação entre Religião e Direito, entre lei divina e lei humana, entre fas e jus. Em Roma, a partir do início da fase clássica (séc. II a.C.), o Direito adquiriu autonomia; passou a ser objeto de uma atividade especial, a jurídica. "Nos últimos séculos da República, as normas jurídicas aparecem nitidamente diferenciadas de todas as outras; são objeto de estudo, ensino e elaboração próprias" (Arangio-Ruiz, “Istituzioni", $\S 2^{\circ}$, p. 23). ${ }^{3}$ O Direito passou, então, a ser um campo especial do saber. Isso não ocorreu na cultura dos outros povos antigos.

A separação feita pelos romanos permaneceu no mundo ocidental; como se sabe, até mesmo no período medieval, de maior influência da Igreja, - apesar de tentativas de exercício do poder temporal pelo Papado ou, inversamente, como nas questões de investidura, de interferência de reis ou imperadores na Igreja - as duas esferas, Direito e Religião, não se confundiram e permaneceram separadas. Eram duas as jurisdições, canônica e civil, e duas as disciplinas de estudo, uma fundada no jus divinum e outra, no Direito Romano, após seu renascimento no séc. XII, podendo, aliás, o estudioso formar-se em ambas, doctor utriusque juris.

\footnotetext{
3 Para bem caracterizar os dois tipos de normas, fas e jus, servem as palavras de Isidoro de Sevilha ("Originum sive Etymologiarium Libri XX", v. 2, apud JHERING, R. von. L'espirit du droit. 3. ed. Tradução de Meulenaere. Paris: Librairie A. Marescq Aîné, 1876. v. 1, § 21, p. 267): "Fas lex divina, jus lex humana est". Em Roma, por ocasião do período clássico, as duas esferas estavam, pois, devidamente separadas; nisso, os autores são concordes (CORREIA, Alexandre; SCIASCIA, Gaetano. Manual de Direito Romano e textos em correspondência com os artigos do Código Civil Brasileiro. 3. ed. São Paulo: Editora Saraiva, 1957. v. 1. § $2^{\circ}$, p. 15; NICOLETTI. Fas. In: NOVÍSSIMO Digesto Italiano. Torino: Utet, 1983. v. 7; DE FRANCISCI, Pietro. Storia del diritto romano. p. 332; etc). As divergências surgem sobre quando exatamente se deu a separação dos dois campos. (JHERING, R. von. op. cit., v. $2, \S 30$, p. 49) sustenta que a dicotomia já existia antes do período histórico. De Francisci, salientando vários resquícios do fas no ius no período histórico (por ex., na confarreatio, na adrogatio, no testamento calatis comitiis, etc), sustenta o contrário, isto é, que de início não havia separação, eis que tanto o ius quanto o fas tinham fundamento religioso. O que nos parece pacífico, tendo em vista a persistência de um rex na República, o "rex sacrorum" (que justamente ocupava a posição mais elevada entre os sacerdotes), é que os romanos, com seu espírito prático, deixaram, por ocasião da mudança do regime político, da monarquia para a república (violenta, segundo a tradição, e lenta, segundo ARANGIO-RUIZ, Vincenzo. Storia del diritto romano. 7. ed. Nápoles: Casa Editrice Dott. Eugenio Jovene, 1974. p. 27 e KUNKEL, Wolfang. Historia del derecho romano. Tradução da 4. edição de Juan Miguel. 3. ed. Barcelona: Ediciones Ariel, 1972. p. 20), as funções religiosas, ligadas ao fas e menos importantes, por força da característica exclusivamente ritual da religião em Roma, para o rex, ficando as funções públicas, ligadas ao jus, para os magistrados. Isto estava caracterizado a partir do início da fase clássica.

Do exposto sobre a separação entre Religião e Direito, percebe-se que a frase de Jesus "a César o que é de César, a Deus o que é de Deus" (Mateus, 22, 21; Marcos 12, 17; e Lucas, 20, 25), altamente inovadora no mundo hebraico, no Oriente, não era assim tão estranha para a civilização romana, no Ocidente.
} 
Entre parêntesis, valeria a pena lembrar, por questões atuais, que até mesmo hoje povos cultos e que mantêm contato com o Ocidente, mas sem a herança romana, não fazem bem essa separação entre Religião e Direito; para eles, a religião ainda "faz" a norma jurídica, como em alguns países muçulmanos. O Alcorão é uma espécie de constituição na Arábia Saudita; no Irã, ele vigora em matéria de família (e tem pouca influência em matéria comercial) etc. Esses povos estão, sob esse aspecto, em situação "pré-romana". Como quer que seja, no mundo ocidental, a separação, teórica e prática, entre Direito e Religião, parece ser um dado civilizacional definitivamente adquirido.

\section{Direito e moral}

O que, porém, os romanos não fizeram e, de uma certa forma, o mundo ocidental, mais de 2.000 anos depois, não resolveu se deve ou-não ocorrer, é a separação entre Direito e moral. Essa questão, de início, já entre os gregos, veio a se propor de forma nítida no séc. V a.C. Nessa época, o desenvolvimento do comércio no Mediterrâneo, o contato especialmente dos atenienses com outras civilizações da região, levou à constatação de que variavam muito os costumes e as leis. Não havia uniformidade de normas jurídicas. A idéia primitiva das cidades isoladas, de que as leis eram imutáveis, promulgadas talvez por algum legislador mítico (Licurgo) ou especial (Sólon) caiu por terra. O filósofo Protágoras (480-411 a.C.), fiel à sua concepção revolucionária de que "o homem é a medida de todas as coisas", sustentou, então, com clareza, e com algum escândalo, que as leis devem ser obedecidas, porque fruto de decisão coletiva, mas que não têm elas nenhuma base natural ou divina. É a sociedade que as estabelece, por convenção; é a sociedade, pela lei do maior número, que resolve o que é certo ou errado. Esse profundo relativismo ético e jurídico - e, nesse passo, seguimos o pensamento de Karl Popper, em "A Sociedade Aberta e Seus Inimigos" - provocou grande angústia a Platão (428-348 a.C.). Esse filósofo, que, com o passar dos anos, parece ter se tornado cada vez mais reacionário e antidemocrático (a tese de Protágoras é que correspondia à recente democracia ateniense), passou a se opor à concepção relativista de Protágoras e a sustentar a existência de normas imutáveis, ainda que somente como princípios - um Direito Natural, isto é, um Direito que, como a natureza, na visão da época, é a mesma em qualquer tempo ou lugar (algo que é, conforme Aristóteles, Ética a Nicômaco, V, em trecho confuso, como o fogo que queima do mesmo jeito na Grécia ou na Pérsia). O 
natural é, pois, o que não muda e o Direito Natural forneceria uma base fixa, definitiva, para as normas jurídicas. ${ }^{4}$

Os romanos, por sua vez, para usar a fórmula do Concílio de Calcedônia (451 d.C.) não confundiram mas também não separaram Direito e moral. O "honestum", conceito fundamental na ética estóica, significava o "moralmente belo" (Cícero, De Officiis, I, V, 15 - o honestum se opõe ao turpe) mas era também o primeiro dos três preceitos do Direito (Ulpiano, D, 1, 10 - "juris praecepta sunt haec: honestum vivere, alterum non laedere, suum cuique tribuere"). ${ }^{5} \mathrm{Na}$ conhecida máxima "nem tudo que é lícito é moralmente belo", "non omme quod licet honeste est", nota-se (i) que não há confusão de conceito entre moral e Direito - o lícito e o honesto não são a mesma coisa - e (ii) também, normalmente, não há, entre eles, separação - por exceção, é que não coincidem. ${ }^{6}$ Em Roma, o Estado tem interesse na moral; a falta de separação entre moral e Direito se comprova pela existência da mais honrosa das magistraturas romanas, a censura, espécie de coroamento da carreira política do homem público; ela tinha essencialmente uma função moral. ${ }^{7}$

\footnotetext{
4 Sobre o antigo Direito Natural ("lex naturalis"), é famoso o trecho de Cícero (106 - 3 A.C.): "Há uma verdadeira lei, razão reta, conforme à natureza, gravada em todos, imutável, eterna, que, ordenando, chama para os deveres, e proibindo afasta o mal, que jamais se dirige inutilmente aos bons, com suas ordens e proibições, mas não move os maus; [...] não é uma lei em Roma e outra em Atenas, uma antes e outra depois, mas é una, sempiterna e imutável, entre todos os povos e em todos os tempos; como uno será o mestre comum e imperador, Deus, criador, sancionador e publicador da lei" ("Est quidem vera lex recta ratio, naturae congruens, diffusa in omnes, constans, sempiterna; quae vocet ad officium jubendo, vetando a fraude deterreat, quae tamen neque probos frustra jubet aut vetat, nec ímprobos jubendo aut vetando movet [...]. Nec erit alia lex Romae, alia Athenis, alia nunc, alia posthac, sed et omnes gentes et omni tempore una lex et sempiterna et immutabilis continebit, unusque erit communis quase magister et imperator omnium Deus; ille legis hujus inventor, disceptator, lator” fragmento do De Re Publica, III, 17).

5 Escrevem (CORREIA, Alexandre; SCIASCIA, Gaetano. op. cit., § 3, p. 18):"Iuris praecepta sunt haec: honeste vivere, alterum non laedere, suum cuique tribuere. Estes preceitos são comuns à moral, mas devem entender-se em função do direito positivo de dado momento histórico. A honestas é muitas vezes encarada como produtora de conseqüências jurídicas; a proibição de lesar os outros encontra no direito a mais eficaz afirmação; e o princípio de dar a cada um o seu é básico na estrutura jurídica romana" (negritos nossos).

${ }^{6}$ Comentando o verso atribuído a Sêneca, “Quod non vetat lex, hoc vetat fieri pudor”, escreve (HENRIOT, Eugène. Moeurs juridiques et judiciaires de l'ancienne Rome. Reimpr. da edição de Paris de 1865. Scientia Verlag Aalen, 1973. tomo I, § XII, p. 53): “C'est la traduction poétique de cet adage si connu du droit romain: "Non omne quod licet honestum est", et de cette autre règle inscrite au Digeste: "Semper, in conjunctionibus, non solum quod licet considerandum est, sed et quod honestum sit". Este último texto - "Sempre nas uniões deve ser considerado não só o que é lícito mas também o que é moralmente correto (o "honestum"), está no D. 23, 2,42, atribuído a Modestino, e também no D. 50, 17, 197.

7 JHERING, R. von. L'espirit du droit. 3. ed. Tradução de Meulenaere. Paris: Librairie A. Marescq Aîné, 1876. v. 1, p. 336: "Ayant ainsi leurs fonctions limitées aux seules cérémonies, les prêtres ne pouvaient avoir aucune influence sur la vie, et ce qui n' avait point d'influence à Rome, n'était aussi que peu estimé. Il y a un contraste caractéristique entre l'influence des prêtres et le pouvoir du censeur: la morale, négligée par la religion, devint une affaire d'administration, et un functionnaire civil reprit la charge de l'instruction et de la discipline
} 


\section{O Direito Natural}

A idéia de Direito Natural teve grande sucesso; era como que um terreno comum à moral e ao Direito. Na dicotomia jus civile e jus gentium, os romanos caracterizaram o último como fruto da razão natural, ("naturalis ratio"). "A naturalis ratio constitui o mais importante elemento dos ius gentium. Considera-se naturalis o que decorre das qualidades físicas dos homens ou das coisas como também o que corresponde a uma ordem normal de interesses humanos e, por isso mesmo, não exige justificações. Quando o ius gentim se identifica como o ius civile, o ius naturale revela-se a Justiniano como um direito estabelecido pela Providência divina (divina quadam providentia constitutum), que é sempre bom e équo (sempre aequum ac bonum)" (Correia-Sciascia, p. 20). ${ }^{8}$

No mesmo diapasão, Santo Agostinho (354-430 d.C.), que caracterizou o homem como social por natureza e anti-social por vício ("nihil est quam hoc genus, tam discordiosum vitio, tam sociale natura” De Civitate Dei, XII, 27), afirma, no final do mundo antigo, nas suas “Confissões” (X, 27, 38), em hino célebre, que Deus está dentro do homem ("Tarde te amei, ó Beleza tão antiga e tão nova, tarde te amei! Estavas dentro de mim e eu mesmo estava fora! E era ai que eu te procurava, nas coisas belas que criastes, sobre elas me arrojando disforme. Estavas comigo e eu não estava contigo!'”). Segue-se daí que, na Idade Média, esse Direito Natural de razão adquiriu ainda mais força, porque foi relacionado a princípios divinos, como que impressos na consciência moral do indivíduo.

morales du peuple" (negritos nossos). E adiante (JHERING, R. von. op. cit., v. 2, p. 50): “Analysons les cas dans lesquels le censeur intervenait. On nous cite comme tels: le parjure, l'adultère, le divorce sans motifs, le célibat, l'inhumanité envers les subordonnés, y compris les esclaves, la débauche, la prodigalité, même le luxe simple, l'altération des rapports économiques, l'exercice désordonné de l'agriculture, la conduite publique blâmable, telle que la brigue de la faveur populaire, la soif des nouveautés, le manque au respect dû à 1'autorité, etc. Cette énumération indique que le pouvoir du censeur ne s'exerçait pas uniquement sur des faits d'immoralité proprement dite; il s'étendait à des actions qui peuvent être considérées comme déraisonnables plutôt qu'immorales, en d'autres termes à des actions dont le diligens paterfamilias romain avait coutume de s'abstenir. Le censeur ne représentait pas seulement les intérêts de la morale, mais aussi ceux de l'économie politique publique ou privée: il était la règle personnifiée de la morale rustique". Todavia, vale lembrar, as decisões do censor, um magistrado, ao contrário das sentenças, não tinham diretamente efeitos jurídicos (cf. Id. Ibid.).

8 Ulpiano, em texto adotado também pelas Institutas de Justiniano (Institutas, I, 2) e por São Tomás ("Summa", $\mathrm{Q}, 57,2$, de $2^{\mathrm{a}}$ Parte da $2^{\mathrm{a}}$ Parte), não identifica o jus naturale com o jus gentium. O Direito Natural, em trecho mal compreendido - mas que tem consistência - é, para Ulpiano, o que "a natureza ensina a todos os animais", "quod natura omnia animalia docuit", animais da terra e do mar e também as aves (D. 1, 1, 3).

9 "Sero te amavi, pulchritudo tam antiqua et tam nova, sero te amavi! Et ecce intus eras et ego foris et ibi te quaerebam et in ista formosa, quae fecisti, deformis inruebam. Mecum eras, et tecum non eram". 
São Tomás de Aquino (1225-1274), por sua vez, na Suma Teológica, afirma com clareza uma duplicidade de fonte das normas jurídicas. Há, em primeiro lugar, as que se formam com conteúdo ético prévio - são as de Direito Natural - há o bem e o mal antes da lei e esta, conforme o caso, ou preceitua ou proíbe; são os "praecepta quia bona" e os "proibita quia mala" (da Q. 57, art II, da 2a Parte da 2a Parte); por exemplo, o preceito de respeitar os pais ou a proibição de matar o inocente. A norma como que consagra o que está na natureza. Há, porém, em segundo lugar, as leis que se formam por decisão, sem conteúdo ético prévio; ao invés de o preceito ordenar, porque a coisa é boa, e a proibição vir, porque a coisa é má, dá-se o contrário; o bem e o mal não existem antes da norma e surgem, o bem, do preceito, e o mal, da proibição. São os casos de "bona quia praecepta" e "mala quia proibita", por exemplo, em termos de hoje, o preceito de guiar pela direita e a proibição de passar com o sinal vermelho. Nesse modo tomista de ver, a questão "moral e direito" se põe claramente: usando, de novo, a fórmula do Concílio de Calcedônia, Direito e moral não se confundem mas também não se separam (a união se faz pelo Direito Natural).

A partir da Renascença, prosseguindo, a admissão do Direito Natural, apesar do progressivo laicismo, não desapareceu. De uma certa forma, até se reafirmou. O que se alterou foi, porém, a maneira de conceber seu conteúdo: deixou de estar ligado à consciência moral ou à uma idéia religiosa e passou a ser considerado como fruto da razão. Especialmente nos séculos XVII e XVIII, os juristas - em geral, os mais conhecidos, ressalvando Grotius (1583-1645), eram franceses, como Domat (1625-1696) e Pothier (1699-1772), e tiveram influência cartesiana, procuraram sistematizar as normas por meio de princípios fundamentais e tirar dedutivamente as conseqüências (método depois chamado de "sintético-compendiário"). Era preciso simplificar o Direito que vinha da Idade Média, um cipoal, e o instrumento para isso era a razão. A conseqüência desse vasto movimento racionalista acabou sendo a feitura do Código Civil francês, ou "Código Napoleão", de 1804, que marca profundamente a História do Direito. De uma certa forma, se inicia aí também o fim da plena aceitação do Direito Natural, porque entramos em tempos de novo paradigma, o da lei.

\section{O positivismo legal}

A excelência do Código Civil francês e, depois, dos demais Códigos, fez com que o jurista, ao invés da razão, procurasse o texto. Pode-se dizer que, a partir daí, cada vez mais quem diz "direito" diz "lei”. Trata-se do positivismo legal. No fundo, 
mais de 2.000 anos depois, deu-se a vingança de Protágoras contra o velho Platão. O homem tornou-se a medida de todas as coisas. O que passou a ter importância foi a decisão coletiva. ${ }^{10} \mathrm{O}$ Direito Natural, então, praticamente desaparece como Direito para a maioria dos juristas; passa a ser quando muito um conjunto de princípios morais mas sem força jurídica coercitiva. O importante é a lei.

Sob o paradigma da lei, a maneira de conceber o Direito correspondia perfeitamente à mentalidade democrática e individualista das nações ocidentais, no séc. XIX e começo do séc. XX. Entretanto, os movimentos sociais, as revoluções, as guerras, os campos de extermínio, em todo o decorrer do séc. XX, puseram em cheque aquela confiança na lei como expressão da vontade coletiva. Especialmente, após a $2^{\mathrm{a}}$ Grande Guerra, os juristas, consciente ou inconscientemente, voltaram a procurar algo que pudesse evitar tanta tragédia para o ser humano. O simples Direito Positivo, afinal, não fora suficiente para impedir a barbárie. Alguns juristas voltaram a falar em "direito supralegal” (evitando a expressão "Direito Natural”) (Bachof, o.c., passim) mas a maior parte procurou reforçar a Constituição e os Direitos Humanos, até mesmo formulando novas declarações de direitos, válidas quaisquer que fossem o Estado e seu regime político (por ex., a Declaração do Direitos da ONU, de 1948).

\section{Daí, a nosso ver, os dois pilares do Direito atual: Constituição e Direitos}

Humanos. Constituem ambos como que os fundamentos últimos da argumentação jurídica hoje. Mas, movidos pela inquietação intelectual, cabe perguntar: esses dois alicerces bastam? Resolvem ambos todas as nossas possíveis dúvidas? Salvo melhor juízo, os dois

\footnotetext{
${ }^{10}$ É interessante a exposição de (POIRIER, Jean-Louis. Les présocratiques. Gallimard: Bibliothèque de La Pléiade NRF, 1988. p. 1.526) sobre o persamento de Protágoras no ponto de que trata o texto: "que l'homme soit mesure de toutes choses, cela signifie, de la manière la plus large et la plus profonde, que rien n'est par nature mais que tout est par convention. (...)Toutes choses sont, pourrait-on dire, d'établissement humain; la stabilité de la nature n'est repérable nulle part, mais lui est substituée partout, une stabilité infondée en théorie, mais produite, et donc effective, par artifice, et qui, quoique théoriquement changeante et changeable, offre des caracteristiques suffisamment assurées; l'ordre qui la définit n'est pas celui de la nature, mais celui de l'art humain: la loi et l'education. Ainsi, l'eau n'est plus l'élément dans lequel on se noie depuis que la convention de la natation apporte le salut aux hommes. La sophistique protagoréenne est bien la toute première, peut-être la plus radicale philosophie des valeurs: ce qui fonde une valeur n'est pas sa vérité mais le fait qu'elle est voulue, ce qui fonde le droit n'est pas la nature mais le fait qu'une société humaine l'accepte. Ainsi est maîtrisée la contradiction: elle devient l'inévitable diversité des établissements humains, diversité qui n'empêche pas certaines valeurs d'être admises par plusieurs; plusieurs qui forment alors une société humaine, cimentée par l'acceptation de ces valeurs, transmises par l'education, création continue des valeurs, pratique fondamentale - c'est-a-dire fondatrice: l'école est la source du savoir, les vérités ne lui viennent pas de la nature ou du monde extérieur - du sophiste. Ainsi, les choses ne sont pas "par nature", mais "par convention", ce qui signifie que l'homme est bien "mesure" de toutes choses, mais qu'il faut admettre la variabilité de cette mesure qui n'est unitaire qu'à l'égard des sociétés qui, dans um vouloir commun, fixent, au sein d'une variation toujours possible, la variété qui convient en ce lieu et en ce temps. La convention n'est pas menacée par la contradiction, car ce qu'elle réclame n'est pas l'universalité, mais la communauté, unité dans la mesure et dans les limites d'une société" (negritos nossos).
} 
pilares, no mínimo, precisam ser "reforçados". Poderíamos seguir simplesmente, criticar o Direito como está e deixar as questões em aberto, seguindo o pensamento de Karl Jaspers ("Way to Wisdom", p. 12) de que compete ao pensador - "filósofo", no sentido próprio e etimológico - antes formular questões, fazer perguntas, que apresentar soluções; mas, por temperamento, vamos criticar e acrescentar algumas palavras sobre os referidos fundamentos. ${ }^{11}$

\section{Crítica ao neopositivismo constitucional}

Sobre o primeiro pilar, a Constituição, vale lembrar que, apesar de ser ela a lei maior, não deixa de ser uma lei como as outras, sujeita às mesmas vicissitudes históricas. Se hoje é uma Constituição que nos agrada, amanhã poderá ser outra, e não agradar. E aí como ficamos? Convem observar que a nossa atual Constituição, em vinte anos, já recebeu mais de 60 emendas! E há sempre a questão da interpretação: lei maior ou lei menor, quem interpreta é o intérprete (é "tautologia expressiva", na expressão de Pontes de Miranda).

Na verdade, todo intérprete, na sua atividade, tem a "pré-compreensão", com que se aproxima do objeto, e traz também consigo a "legal culture" e as idéias em geral próprias do seu tempo. Terá critérios, pois, metajurídicos, que cumpre explicitar para bem avaliar. No fundo, há sempre a mesma questão que se põe ao positivismo legal - no caso, ao neopositivismo constitucional: o texto basta? Ainda que se diga que, no primeiro positivismo, a interpretação era "mecânica", "de subsunção", "dedutiva", etc. e que agora, é tipológica, guiada por princípios, teleológica, etc., a verdade é que o Direito não é somente lei. O texto não basta.

Não se trata, porém, de recolocar ao lado Direito Positivo, o velho Direito Natural (lex naturalis, à moda de Cícero e dos escolásticos em geral) porque, desde 1859, com Darwin, o conceito de natureza imutável explodiu. ${ }^{12}$ A natureza evolui. Há nela, porém,

\footnotetext{
11 JASPERS, Karl. Way to wisdom. Tradução de Ralph Manheim. New Haven/Londres: Yale Nota Bene. 2003: "What then is this philosophy, which manifests itseft so universally and in such strange forms? The Greek word for philosopher (philosophos) connotes a distinction from sophos. It signifies the lover of wisdom (knowledge) as distinguished from him who considers himself wise in the possession of knowledge. This meaning of the word still endures: the essence of philosophy is not the possession of truth but the search for truth, regardless of how many philosophers may belive it with their dogmatism, that is, with a body of didactic principles purporting to be definitive and complete. Philosophy means to be on the way. Its questions are more essential than its answers, and every answer becomes a new question".

${ }^{12}$ Infelizmente, no mundo jurídico ainda prevalece uma mentalidade pré-darwiniana. Escreve DAWKINS, Richard. The selfish gene. Nova York: Oxford University Press, 1989. p. 1: "Philosophy and the subjects known as 'humanities' are still taught almost as if Darwin had never lived' (negritos nossos). Há exagero, mas algo de verdadeiro na fase de G.G.Simpson (apud Dawkins idem, ibidem): "The point I want to make
} 
um bem permanente, algo com valor ontológico, a vida - é este o valor a explicitar. A vida é um valor natural. Começou no planeta Terra há 4 bilhões de anos e prossegue. A crítica de Hume de que do ser não se tira o dever ser, aceita por Kant e pensadores posteriores, não é verdadeira; como diz Hans Jonas (p. 96 e ss.), aquela formulação parte de uma premissa falsa, de um engano, porque já de início reduz a natureza, isto é, já de início, o argumento, em petição de princípio, esvazia a natureza do seu maior valor, a vida. A vida, quer a vida em geral, quer a vida humana em particular, está acima do direito posto. É, qualquer que seja a constituição, bem supra-constitucional. ${ }^{13}$

Por outro lado, o próprio Direito posto não é somente norma. O Direito é sistema, e sistema de $2^{\mathrm{a}}$ ordem, porque é instrumento da sociedade criado com a função de prevenir e dirimir conflitos. O Direito é sistema, entendida a palavra "sistema" no âmbito da sistêmica, ou seja, enquanto o Direito concebido como norma tem caracterização estática e piramidal, com a Constituição no ápice e a legislação ordinária abaixo, agora, aqui, ao falar em "sistema", estamos procurando introduzir um aspecto dinâmico, em que "sistema" é entendido como um conjunto de elementos que evoluem e interagem de modo relativamente uniforme, - como o sistema solar, na astronomia, ou as células, na Biologia. Os elementos do sistema jurídico são, (i) além das normas, que precisam sempre de interpretação, (ii) as instituições jurídicas, como os parlamentos, as assembléias e os tribunais; (iii) os membros do estamento jurídico, como advogados, promotores e juízes; (iv) a doutrina; e (v) a jurisprudência. Advogados e promotores, por exemplo, são órgãos de input porque põem os conflitos para dentro do sistema jurídico para obter solução; os juízes, por sua vez, são órgãos de output, porque procuram solucionar as questões na vida social. $^{14}$

Com a idéia de sistema de $2^{\mathrm{a}}$ ordem, o Direito incorpora-se à toda a vida social, o sistema maior, e passa a se justificar não-somente pela lei do maior número mas, via interpretação, por todo um processo de argumentação “sensível à verdade", no dizer de

\footnotetext{
now is that all attempts to answer that question before 1859 are worthless and that we will be better off if we ignore them completely".

13 Observamos que, tecnicamente, a vida em geral e a vida humana em particular são bens naturais mas não são propriamente "direitos" naturais. A própria vida humana não é um direito subjetivo ou um dos "direitos" humanos, porque as pessoas não tem direito sobre a vida; têm somente direito a defender a vida, mas não, a dela dispor. Por outro lado, a vida é um bem e um valor o "bem" é em si e o "valor" é a expressão do bem.

14 O Direito é um sistema que chamamos de $2^{\mathrm{a}}$ ordem, por estar em função do sistema maior, a sociedade. Ele é, no nosso entendimento, como o sistema nervoso no corpo humano ou animal, que é dito sistema de $2^{\mathrm{a}}$ ordem por Maturana e Varela (p. 153). Por outro lado, apesar de falarmos em input e output, o direito não é um computador (cf. também LE MOIGNE, Jean-Louis. La théorie du système general. 4. ed. Paris: PUF, 1977. p. 18 e ss.).
} 
Habermas que preferimos dizer "processo de argumentação sensível ao que é socialmente útil", dando mais legitimidade à própria Constituição e às leis em geral.

\section{Insuficiência dos Direitos Humanos}

O outro pilar do Direito atual, o dos Direitos Humanos, sintetizado na expressão "dignidade da pessoa humana", também pode passar por aperfeiçoamento teórico, porque, como está, não permanece isento de críticas. Antes de mais nada, é preciso se conscientizar de que, como afirmava Michel Villey (o.c., passim), se todos nós temos "direitos humanos", há necessidade, para harmonizar os Direitos Humanos de cada qual, de regras a eles superiores. A vida é um imperativo absoluto mas os Direitos Humanos em geral não estão na mesma situação e precisam se compor; por exemplo, se a pessoa pública - prefeito, governador - tem direito ao resguardo da própria intimidade, como conciliar esse direito com o direito à informação da mídia e com o direito a ser informado do povo? Se há direito à proteção da casa, como residência, como admitir a cessão dela como garantia penhorável? Os problemas são muitos e não basta alegar direitos humanos para se obter solução; faltam regras mais precisas de composição.

Por fim, os Direitos Humanos, concebidos sob a idéia iluminista das declarações de direito do séc. XVIII e com base no personalismo ético de fonte kantiana, a nosso ver, ficaram incompletos, a partir da já referida descoberta da evolução por Darwin. Dizia Kant, em trecho famoso dos "Fundamentos da Metafísica dos Costumes" (p. 69 e 80), que todas as coisas têm preço e o homem, dignidade. Segue-se daí, como aliás está no nosso Código Civil do século XXI, que a separação é radical: de um lado, há a pessoa (inclusive jurídica), sujeito de direito, e de outro, há as "coisas", objeto de direito. Ora, nessa concepção, o animal é coisa - o que não é verdade. Essa qualificação já não ocorre no Código Civil da Áustria, da Suíça e da Alemanha; neles, o Direito Civil evoluiu para dispor expressamente (por exemplo, § 90-A do BGB) que o animal não é coisa. A descoberta da evolução não só pôs por terra a idéia de que a natureza é imutável - há mutação das espécies - como nos obriga a acordar para o valor da "vida" inclusive dos animais. Talvez não seja o caso de admitirmos "direitos dos animais", mas nos parece inegável que pelo menos os animais superiores são titulares de "interesses protegidos". 15

\footnotetext{
15 Defendem os "direitos" dos animais, Peter Singer, Tom Reagan e "ativistas" em várias partes do mundo. Todavia, são mais interessantes, para a valorização dos animais, os trabalhos do primatologista De Waal ("Good Natured", "Primates and Philosophers") e dos etologistas, em geral.
} 
7. Conclusão

Em síntese, é preciso, hoje, ultrapassar o neopositivismo constitucional e a limitação dos Direitos Humanos, seja corrigindo ou completando o Direito atual com a idéia de Direito como sistema de $2^{\mathrm{a}}$ ordem, cuja função é prevenir e solucionar conflitos, seja, paralelamente, aumentando e aprofundando os Direitos Humanos com o reconhecimento do valor ontológico da vida.

São Paulo, dezembro de 2007.

\section{Referências}

ARANGIO-RUIZ, Vincenzo. Storia del diritto romano. 7. ed. Nápoles: Casa Editrice Dott. Eugenio Jovene, 1957.

ARANGIO-RUIZ, Vincenzo. Istituzioni di diritto romano. 14. ed. Nápoles: Casa Editrice Dott. Eugenio Jovene, 1974.

ARISTÓTELES. Ética a Nicômaco. Tradução de Maria Araújo e Julian Marias. Edição bilíngüe. Madri: Institutos de Estudios Politicos, 1970.

AGOSTINHO, Santo. Confessiones. Edição bilíngüe. Paris: Les Belles Lettres, 1969. Tomo II.

AGOSTINHO, Santo. De Civitate Dei. Tradução de Santos Santamarta del Rio e Miguel Fuentes Lanero. Edição bilíngüe. Madri: BAC, 1977.

BACHOF, Otto. Normas Constitucionais Inconstitucionais? Tradução de José Manuel M. Cardoso da Costa. Coimbra: Livraria Almedina, 1994.

CÍCERO, Marco Túlio. De Officiis. Tradução de Maurice Testard. Edição bilíngüe. Paris: Les Belles Lettres, 1974.

CÍCERO, Marco Túlio. De Re Publica. London: Heinemann, 1951.

CORREIA, Alexandre; SCIASCIA, Gaetano. Manual de Direito Romano e textos em correspondência com os artigos do Código Civil Brasileiro. 3. ed. São Paulo: Editora Saraiva, 1957. v. 1.

DAWKINS, Richard. The Selfish Gene. Nova York: Oxford University Press, 1989.

DE FRANCISCI, Pietro. Storia del diritto romano. Milão: Dott. A. Giuffrè, 1943. v. 1. 
DE WALL, Frans. Primates and Philosophers: How Morality Evolved. Princeton and Oxford, 2006.

DE WALL, Frans. Good Natured: the origins of right and wrong in humans and other animals. Cambridge / Londres: Havard University Press, 1996.

HENRIOT, Eugène. Moeurs juridiques et judiciaires de l'ancienne Rome. Reimpr. da edição de Paris de 1865. Scientia Verlag Aalen, 1973. Tomo I.

JASPERS, Karl. Way to Wisdom. Tradução de Ralph Manheim. New Haven / Londres: Yale Nota Bene, 2003.

JHERING, R. Von. L'esprit du droit romain. Tradução de Meulenaere. 3. ed. Paris: Librairie A. Marescq Aîné, 1876. v. 1. e 2.

. Le principe responsabilité. Une éthique pour la civilisation technologique. Tradução de Jean Greisch da edição de 1979. Paris: Flammarion, 1990.

KANT, Emmanuel. Des fondements de la métaphysique des moeurs. In: Critique de la raison pratique. Tradução de J. Barni. Paris: Librairie Philosophique de Ladrange, 1848.

KUNKEL, Wolfgang. Historia del derecho romano. Tradução da 4. edi. alemã por Juan Miguel. 3. ed. Barcelona: Ediciones Ariel, 1972.

LE MOIGNE, Jean-Louis. La théorie du système general. 4. ed. Paris: PUF, 1977.

MATURANA, H.; VARELA, Francisco J. The Tree of Knowedge. Tradução de Roberto Paolucci. Boston / Londres: Shambhala, 1988.

NICOLETTI. Fas. In: Novíssimo Digesto Italiano. UTET, 1983. v. 7.

POIRIER, Jean-Louis. Les présocratiques. Gallimard: Bibliothèque de La Pléiade NRF, 1988.

TOMÁS DE AQUINO, Santo. Suma Teológica. 2. ed. Tradução de Alexandre Corrêa. Porto Alegre: Livraria Sulina Editora, 1980. v. 5.

VILLEY, Michel. Le droit et les droits de l'homme. Paris: PUF, 1983. 